\title{
Incidence and risk factors of periparturient conditions in smallholder dairy cattle herds in Kikuyu Division of Kiambu District, Kenya
}

\author{
Abuom T.O.*, Njenga M.J., Wabacha J.K., Tsuma V.T. and Gitau G.K. \\ Department of Clinical Studies, University of Nairobi, P.O. Box 29053-00625, Nairobi Kenya \\ * Corresponding author: Tel.: +254 020-2055199/8 \\ E-mail address:toabuom@uonbi.ac.ke / okumutequiero@yahoo.com
}

\begin{abstract}
A study was carried out on 117 smallholder dairy cattle herds in Kikuyu Division of Kiambu District Kenya between April 2004 and December 2004 to determine the incidence of periparturient conditions (downer cow syndrome, dystocia, milk fever and retained placenta among others) in smallholder dairy cattle herds and the associated factors (plausible predictor variables; age, parity and management systems among others) from a total of 206 dairy cattle. Data were collected during farm visits by observation, interviews using semi-structured questionnaires and clinical examination of animals. The most common conditions encountered were downer cow syndrome (12.6\%), dystocia (17.0\%), mastitis $(9.5 \%)$, metritis $(7.3 \%)$ milk fever (13\%) and retained afterbirth (26.6\%). The overall cumulative incidence of the periparturient conditions was $67 \%$. Animals with milk fever were 5 times more likely to develop retained placenta $(\mathrm{P}=0.04)$ while those with a history of having developed retained placenta in a previous parturition were at 2 times more likely to develop retained afterbirth $(\mathrm{P}=0.05)$. Cows with milk fever were 9 times more likely to develop owner cow syndrome $(\mathrm{P}<0.001)$ while those that were not given supplemental feed in the last trimester were 4.8 times more likely to develop downer cow syndrome $(\mathrm{P}=0.007)$. Animals that had dystocia were 3.9 times more likely to develop metritis $(\mathrm{P}=0.02)$ and while those with retained placenta were 5.2 times more likely to develop metritis $(\mathrm{P}=0.03)$. In addition, animals with dystocia were 10.55 times more likely to develop postpartum haemorrhage $(\mathrm{P}=0.01)$ and 58.9 times more likely to develop injuries to the birth canal $(\mathrm{P}<0.01)$. From this study it can be concluded that downer cow syndrome, dystocia, mastitis, metritis, milk fever and retained placenta were the most common periparturient conditions in smallholder dairy cattle herds in Kikuyu division of Kiambu district.
\end{abstract}

Keywords: Smallholder production, cattle, periparturient conditions, risk factors, Kenya

http://dx.doi.org/10.4314/evj.v16i2.8 


\section{Introduction}

The periparturient period in cattle refers to the 2-3 weeks pre- and post-partum and is a transitional period characterized by changes in endocrine status of the animal, to provide for lactogenesis and parturition. It is also characterized by changes in tissue metabolism, nutrient utilization, and disruptions in functioning of the immune system (Kimura et al., 2006). The initial stages of uterine involution, in preparation for the next reproductive cycle also take place at this time.

Several conditions such as milk fever, ketosis, injuries to the birth canal, nerve paralysis, mastitis and metritis occur at higher frequency during the periparturient period in cattle (Goff and Horst, 1997). These conditions have been reported to account for up to 8 percent of all the diseases in dairy cattle (Roine and Saloniemi, 1978; Markusfeld, 1987), and cause substantial losses to the dairy industry in terms of increased generation interval, loss of genetic pool, deaths, reduced productivity of the animals and costs of treatment (Erb et al., 1985).

Most reports on periparturient conditions have been based on intensively managed large dairy herds in temperate climates (Erb et al., 1985; Markusfeld, 1987; Peeler et al, 1994; Kelton et al, 1998; Radostits et al., 2000). However there is limited information about these conditions in the smallholder dairy production system in the tropics. Since these diseases account for up to 8 percent of all the diseases affecting dairy cattle as has been reported in intensive large-scale herds in temperate countries, these diseases could have economic significance in smallholder herds. Smallholder dairy farming accounts for up to 80 percent of milk production in Kenya (EAAPP, 2010). Thus, suboptimal production due to these diseases will have a significant effect on the national milk production. This study was, therefore, designed to determine the incidence of periparturient conditions and their risk factors in 117 smallholder dairy cattle herds in Kikuyu Division of Kiambu District, Kenya.

\section{Materials and methods}

\section{Study area}

This study was carried out in Kikuyu Division of Kiambu District, Central Kenya between April and December 2004. Kikuyu Division covers an area estimated at 240 square kilometers and is divided into two main agroecological zones, namely the lower highland (L.H.) with an altitude of between 1820 to $2070 \mathrm{~m}$ 
above sea level and the upper midland (U.M.), with an altitude of between 1200$1820 \mathrm{~m}$ above sea level. Mean temperatures are mainly determined by altitude ranging from $8.6 \mathrm{oC}$ to $21.9 \mathrm{oC}$ in the lower highland and $13.1 \mathrm{oC}$ to $22.9 \mathrm{oC}$ in the upper midland agro-ecological zone. The rainfall in this area is bimodal and reliable with the long rains occurring between the months of March and May while the short rains occur from October to December. Average rainfall is $800-2000 \mathrm{~mm} /$ annum and $600-1600 \mathrm{~mm} /$ annum in the lower highland and upper midland agro-ecological zones, respectively. The total cattle population in this area is estimated at 35,000 most of them being dairy cattle that are intensively reared (Mars group, 2012).

\section{Sampling method and sample size}

Initially, smallholder farms having less than 10 dairy cattle were selected from a list at the Kikuyu Dairy Cooperative Society and the local livestock production office.. The selection of the herds and animals was purposive and progressive based on the presence of at least one animal 3-8 months pregnant in the herd and the farmers' willingness to participate in the study. The pregnancies were confirmed by trans-rectal palpation of the uterine contents. A total of 117 (88.6 $\%)$ out of the 132 smallholder farmers interviewed were willing to participate in the study. Some of the farmers who were unwilling to cooperate thought that a rectal palpation in a pregnant animal would affect the survival of the foetus in-utero or the calf post-calving; others on the other hand did not see how the study would be of benefit to their animals.

Farmers were motivated by being offered free treatment for any sick animal in the herd by the first author.

The smple size was determined using the formula

$$
\mathrm{n}=\frac{4 \mathrm{XP}(1-\mathrm{P})}{\mathrm{L} 2}
$$

where $\mathrm{n}=$ sample size, $\mathrm{L}=$ Precision $(0.05)$ and $\mathrm{P}=$ prevalence estimate $(20 \%)$, using $95 \%$ confidence levels

$\mathrm{P}$ was estimated at 0.5

One hundred and fifty animals were from the lower highland agro-ecological zone (Altitude 1820 - $2070 \mathrm{~m}$ above sea level) and 56 from the upper midland agroecological zone (Altitude 1200-1820m above sea level). Follow up for 113 animals took place during the dry season while the remaining 93 were

Ethiop. Vet. J., 2012, 16 (2), 85-102 
followed during the wet season. The follow-up period was a seasonal coincidence and was not to affect the study outcome. The breeds of the animals were identified phenotypically and the ages of the animals were determined through dentition (Sisson and Grossman, 1969). The animals selected were of varying ages and parities and almost exclusively of exotic breeds with Friesians being the most common breed as shown in

Table 1;Lactational incidence rates of periparturient conditions in smallholder dairy cattle herds in Kikuyu Division of Kiambu District (April 2004-December 2004)

\begin{tabular}{lcc}
\hline Disease/condition & Number of animals & Herd incidence (\%) \\
\hline Cystic ovarian disease & 1 & 0.5 \\
Displaced abomasum & 0 & 0.0 \\
Downer cow syndrome & 18 & 8.7 \\
Dystocia & 28 & 13.6 \\
Injuries to the birth canal & 9 & 4.4 \\
Ketosis & 1 & 0.5 \\
Mastitis & 20 & 9.7 \\
Metritis & 13 & 6.3 \\
Milk fever & 23 & 11.2 \\
Nerve paralysis & 2 & 1.0 \\
Physiological oedema & 8 & 3.9 \\
Postpartum haemorrhage & 5 & 3.2 \\
Retained placenta & 58 & 28.2 \\
Stillbirth & 12 & 5.8 \\
Uterine and vaginal prolapse & 8 & 3.9 \\
Uterine torsion & 1 & 0.5 \\
\hline
\end{tabular}

\section{Visits to farms}

Monthly visits were carried out for pregnant animals that had not entered the periparturient period (more than 3 weeks prior to parturition) and weekly visits were carried out as soon as the animals entered the periparturient period (3 weeks before and 3 weeks after parturition). During the first visit to the farm, baseline herd data were collected by the main author through direct observation and administration of a self administered semi-structured questionnaire. The questionnaire was in English, but when necessary, translation to Kiswahili (national language) was done by the main author while a veterinary assistant did the translation to Kikuyu (local dialect). The data collected included the farm location, management system, herd structure, feeding system and breeding practices. The level of hygiene and maintenance of farmstructures were visually scored as good, fair or poor. During the initial and subsequent 
visits, detailed data about individual cows/heifers participating in the study were collected using a clinical record form. These included animal identification, age, parity, its reproductive history and present medical and fertility status as determined by a detailed physical examination. A trans-rectal examination was performed to determine the pregnancy status, age of pregnancy and the presence or absence of uterine infection post partum.

\section{Case definitions}

Cystic ovarian disease- A case of cystic ovarian disease was based on history of anoestrus and nymphomania, palpation of ovaries and detection of a cyst that was greater than $2.5 \mathrm{~cm}$ in diameter and lasted for more than 10 days. Those that were thin walled were classified as follicular cysts while those that were thick-walled were classified as luteal cysts. In addition, clinical signs sinking of sacrosciaticligaments, masculinization and short inter-oestrus intervals were also considered.

Displaced abomasum- A case of displaced abomasum was based on history of inappetance combined with clinical signs of reduction in frequency and intensity of rumen movements, high pitched tinkling sounds in the left or right side in the area around the $9^{\text {th }}-13^{\text {th }}$ ribs and rectal palpation for right displacement of the abomasum.

Downer cow syndrome- An animal that was unable to rise after 24 hours of recumbency or unresponsive to two treatments for milk fever was termed a downer cow.

Dystocia- Dystocia was determined based on the history of occurrence from the farmer and clinical examination of the dam and foetus per vaginum to determine the type and the cause of the dystocia.

Injuries to the birth canal- This was determined based on history from the farmer and careful examination of the perineum, vulva, vagina and uterus for tears and injuries.

Ketosis- Ketosis was determined using clinical signs of wasting, decreased or selective appetite preferring to eat roughage and less concentrate, ketone odour in breath and milk and nervous signs. Tests were also performed on urine to confirm the occurrence of ketosis using dipsticks. Ten millilitres of urine was collected into a test tube and the dipstick dipped into the urine sample for five seconds and the reading done immediately on a scale. The results were 
classified as either negative,,+++ or +++ depending on the levels of ketones (Combur10 Test@; Boehringer, Mannheim).

Mastitis - Mastitis was determined based on history of occurrence from the farmer and gross changes in the udder, milk and the animal. The Californian Mastitis Test (CMT) was performed to screen for mastitis at the farm and visually scored as 1, 2, 3, 4 or 5 (Grootenhuis et al, 1979). Thereafter, milk from all CMT positive quarters from animals was collected aseptically into sterile universal bottles and transported to the laboratory in a cool box for culture and sensitivity testing.

Puerperal metritis- This was determined based on the history of occurrence, general examination for the presence of fetid vaginal discharges, straining by the cow, inflammation and oedema of the vulva and rectal examination of the uterus for its size and contents.

Milk fever - This was determined based on history of occurrence and clinical signs such as reduced rectal temperature, depressed mental state, dry muzzle, weak pulse and heart sounds, generalized muscle weakness, ruminal atony and tympany, dilation of pupils with slow pupillary light reflex and recumbency.

Physiological oedema- This was determined based on history of occurrence and clinical examination of oedematous swelling on and around the udder.

Postpartum haemorrhage- This was determined based on history from the farmer and clinical signs of blood oozing from the vulva, pale mucous membranes, tachycardia and tachypnoea.

Retained placenta- This was determined based on the history of a placenta that had not dropped within 12 hours after calving and observation of the placenta hanging outside the vaginal opening or physical palpation per-vaginum.

Stillbirth-This was determined based on observation and history of birth of a dead foetus at term or within 24 hours after birth.

Uterine and vaginal prolapse- This was determined based on the history of occurrence from the farmer and the clinical observation of the organ hanging outside the vulva opening.

Uterine torsion- This was determined based on history of a cow in the second stage of labour that had been unable to deliver for a prolonged period and clinical examination of the birth canal for twists in the cervix and vagina or 
occlusion. A rectal palpation was performed to determine the direction of the torsion and tension on the broad ligament was used to gauge the severity.

The occurrence of a specific condition was only considered once during its first occurrence per animal even if there was recurrence during the periparturient period

\section{Data management and analysis}

Data were entered and stored in Microsoft Office Excel 2003 (Microsoft Corporation, USA). Conditions were recorded as binary variables ( $1=$ Disease; $0=$ No disease) and the files were screened for any errors that might have occurred during data entry and these were corrected. The data were later exported into Genstat for Windows Discovery Edition 2 (VSN international) for analysis.

Descriptive statistics was computed for age, parity, breed, sex of offspring, agroecological zone, feeding and management systems. The lactational incidence risk (L.I.R.) was used to estimate the incidence of periparturient conditions. L.I.R. has been recommended for calculating the incidence of periparturient conditions due to the short period of risk associated with these conditions (Peeler et al, 1994; Kelton et al, 1998).

The Lactational incidence risk was calculated as

Number of cases

Number of animals at risk

The $\mathrm{X}^{2}$ statistic was used to determine unconditional associations between predictor variables (age, agroecological zone, breed, feed supplementation, level of hygiene, management system, parity, sex of offspring) and periparturient conditions with a significant level of $\mathrm{P}<0.05$ (Dohoo et al, 1996).

Multiple logistic regression procedure was carried out to model the effects of potential risk factors/independent factors on the occurrence of periparturient conditions/dependent factors. The backward elimination procedure was used to eliminate the factors that were not significant at $\mathrm{P}<0.05$ in the overall model. Correlation between parameter estimates was used to determine if any of the variables were correlated. The effect of clustering was controlled by changing the dispersion parameter from 1 to estimate; and comparing the two outputs from the regression models. 


\section{Results}

Disease incidence distribution across altitude, parity and breeds

Most, $67 \%$, (138/206), animals developed at least one of the periparturient conditions under study. The incidences of the periparturient conditions are as given in Table 1.

The incidence of injuries to the birth canal, metritis, retained placenta and stillbirths were higher though not significantly $(\mathrm{P}>0.05)$ in lower highland altitude while the incidence of downer cow syndrome and physiological oedema were higher though not significantly $(\mathrm{P}>0.05)$ in upper midland - altitude. The rest of the conditions were distributed as shown in

Table 2:Incidence of periparturient conditions by parity in smallholder dairy cattle herds in Kikuyu Division of Kiambu district (April 2004-December 2004).

\begin{tabular}{lcccccc}
\hline Condition & $\begin{array}{c}\text { Parity } \\
\mathbf{( 5 3 )}\end{array}$ & $\begin{array}{c}\text { Parity } \mathbf{2} \\
\mathbf{( 5 6 )}\end{array}$ & $\begin{array}{c}\text { Parity } \\
\mathbf{( 3 8 )}\end{array}$ & $\begin{array}{c}\text { Parity } \\
\mathbf{4}(\mathbf{3 2})\end{array}$ & $\begin{array}{c}\text { Parity } \\
\mathbf{5 ( 1 8 )}\end{array}$ & $\begin{array}{c}\text { Parities } \\
\mathbf{6} \mathbf{7} \mathbf{8} \mathbf{8}(\mathbf{9})\end{array}$ \\
\hline Cystic ovarian disease & 0 & 0 & 0 & 0 & 0 & 11.1 \\
Displaced abomasum & 0 & 0 & 0 & 0 & 0 & 0 \\
Downer cow syndrome & 7.5 & 8.9 & 7.8 & 15.6 & 5.5 & 11.1 \\
Dystocia & 23 & 12.5 & 8 & 15.6 & 5.5 & 0 \\
Injuries to the birth canal & 9.4 & 1.7 & 5.2 & 6.2 & 0 & 0 \\
Ketosis & 0 & 0 & 0 & 0 & 5.5 & 0 \\
Mastitis & 11.3 & 8.9 & 0 & 6.2 & 33 & 11.1 \\
Metritis & 11.3 & 8.9 & 2.6 & 0 & 5.5 & 0 \\
Milk fever & 5.6 & 12.5 & 13.1 & 15.6 & 5.5 & 11.1 \\
Nerve paralysis & 3.7 & 0 & 0 & 0 & 0 & 0 \\
Physiological oedema & 5.6 & 5.3 & 2.6 & 3.1 & 0 & 0 \\
Postpartum haemorrhage & 3.7 & 1.7 & 2.6 & 3.1 & 0 & 0 \\
Retained placenta & 28 & 30 & 23 & 25 & 33 & 22.2 \\
Stillbirth & 9.4 & 5.3 & 5.2 & 6.2 & 0 & 0 \\
Uterine and vaginal prolapse & 1.8 & 1.7 & 5.2 & 9.3 & 5.5 & 0 \\
Uterine torsion & 0 & 0 & 0 & 0 & 5.5 & 0 \\
\hline
\end{tabular}

Figures in brackets represent the absolute number of cows in each category

Among the breeds, Friesians were the most common and developed all the conditions under study apart from ketosis and displaced abomasum. Zebu crosses that were the least common breed encountered only developed retained afterbirth. The rest of the breeds developed the various conditions in varying proportions as presented in Table 3. 
Table 3: Incidence of periparturient conditions by breed in smallholder dairy cattle herds in Kikuyu Division of Kiambu district (April 2004-December 2004).

\begin{tabular}{|c|c|c|c|c|c|}
\hline Disease/Condition & $\begin{array}{c}\text { Friesian } \\
+ \text { crosses } \\
(133)\end{array}$ & $\begin{array}{c}\text { Ayrshire } \\
+ \text { crosses } \\
\text { (54) }\end{array}$ & $\begin{array}{c}\text { Jersey } \\
+ \text { crosses } \\
\text { (12) }\end{array}$ & $\begin{array}{c}\text { Guernsey } \\
+ \text { crosses } \\
\text { (5) }\end{array}$ & $\begin{array}{c}\text { Zebu } \\
\text { crosses } \\
\text { (2) }\end{array}$ \\
\hline Cystic ovarian disease & 0.8 & 0 & 0 & 0 & 0 \\
\hline Displaced abomasum & 0 & 0 & 0 & 0 & 0 \\
\hline Downer cow syndrome & 10.5 & 5.5 & 0 & 20 & 0 \\
\hline Dystocia & 10.5 & 14.8 & 33.3 & 40 & 0 \\
\hline Injuries to the birth canal & 5.3 & 3.7 & 0 & 0 & 0 \\
\hline Ketosis & 0 & 1.8 & 0 & 0 & 0 \\
\hline Mastitis & 10.5 & 9.3 & 0 & 20 & 0 \\
\hline Metritis & 5.3 & 7.4 & 8.3 & 20 & 0 \\
\hline Milk fever & 12 & 11.1 & 8.3 & 0 & 0 \\
\hline Nerve paralysis & 1.5 & 0 & 0 & 0 & 0 \\
\hline Physiological oedema & 6.0 & 0 & 0 & 0 & 0 \\
\hline Postpartum haemorrhage & 2.2 & 3.7 & 0 & 0 & 0 \\
\hline Retained placenta & 21.8 & 31.4 & 66.6 & 60 & 50 \\
\hline Still birth & 3.7 & 11.1 & 8.3 & 0 & 0 \\
\hline Uterine and vaginal prolapse & 5.3 & 1.8 & 0 & 0 & 0 \\
\hline Uterine torsion & 0.8 & 0 & 0 & 0 & 0 \\
\hline
\end{tabular}

Figures in brackets represent the absolute number of cows in each category

\section{Risk factors for periparturient conditions}

Risk factors for periparturient conditions are as shown in Table 4. Factors significantly associated with the development of retained afterbirth were milk fever and history of having developed retained afterbirth in a previous parturition. Factors significantly associated with the development of downer cow syndrome were milk fever and lack of supplemental feeding. Factors significantly associated with the development of metritis were dystocia and retained placenta. Dystocia was significantly associated with the development of periparturient haemorrhage and injuries to the birth canal. 
Table 4: Risk factors of periparturient conditions after adjusting for confounding in regression modelling in small-holder dairy cattle herds in Kikuyu Division of Kiambu District (April 2004-December 2004)

Downer cow syndrome

\begin{tabular}{|c|c|c|c|c|c|c|}
\hline Parameter & $\underset{\text { estimate }}{\beta}$ & $\begin{array}{l}\text { Standard } \\
\text { error }\end{array}$ & \multicolumn{2}{|c|}{$95 \%$ confidence limits } & odds ratio & P-value \\
\hline Constant & -3.549 & 0.472 & & & & $<0.001$ \\
\hline aMilk fever & 2.288 & 0.643 & -0.0108 & 4.57708 & 9.3 & $<0.001$ \\
\hline $\begin{array}{l}\text { Lack of } \\
\text { Supplemental }\end{array}$ & 1.760 & 0.656 & 0.0996 & 3.51004 & 4.8 & 0.007 \\
\hline \multicolumn{7}{|c|}{ Injuries to the birth canal } \\
\hline Parameter & $\begin{array}{c}\beta \\
\text { estimate }\end{array}$ & $\begin{array}{l}\text { Standard } \\
\text { error }\end{array}$ & \multicolumn{2}{|c|}{$95 \%$ confidence $\underline{\text { limits }}$} & odds ratio & P-value \\
\hline Constant & -3.356 & 0.415 & & & & $<0.001$ \\
\hline aDystocia & 2.349 & 0.589 & 0.054 & 4.8776 & 58.96 & $<0.001$ \\
\hline \multicolumn{7}{|l|}{ Metritis } \\
\hline Parameter & $\underset{\text { estimate }}{\beta}$ & $\begin{array}{l}\text { Standard } \\
\text { error }\end{array}$ & \multicolumn{2}{|c|}{$95 \%$ confidence limits } & odds ratio & P-value \\
\hline Constant & -3.579 & 0.555 & & & & $<0.001$ \\
\hline aDystocia & 1.618 & 0.702 & 0.0034 & 3.2326 & 3.9 & 0.021 \\
\hline $\begin{array}{l}\text { aRetained } \\
\text { placenta }\end{array}$ & 1.467 & 0.659 & 0.00257 & 2.93657 & 5.2 & 0.026 \\
\hline \multicolumn{7}{|c|}{ Postpartum haemorrhage } \\
\hline Parameter & $\underset{\text { estimate }}{\beta}$ & $\begin{array}{l}\text { Standard } \\
\text { error }\end{array}$ & \multicolumn{2}{|c|}{$95 \%$ confidence limits } & odds ratio & P-value \\
\hline Constant & -4.477 & 0.710 & & & & $<0.001$ \\
\hline aDystocia & 2.357 & 0.937 & -0.00424 & 4.71824 & 10.55 & 0.012 \\
\hline \multicolumn{7}{|c|}{ Retained placenta } \\
\hline Parameter & $\begin{array}{c}\boldsymbol{\beta} \\
\text { estimate }\end{array}$ & $\begin{array}{l}\text { Standard } \\
\text { error }\end{array}$ & \multicolumn{2}{|c|}{$95 \%$ confidence limits } & odds ratio & P-value \\
\hline Constant & 0.078 & 0.507 & & & & $<0.001$ \\
\hline Medical history & -1.068 & 0.532 & -0.00132 & 2.13732 & 2.37 & 0.045 \\
\hline aMilk fever & -1.585 & 0.777 & -0.00008 & -3.17008 & 5.2 & 0.041 \\
\hline
\end{tabular}

a Periparturient conditions that were interrelated

\section{Discussion}

The results of this study showed the incidence of periparturient conditions among the mallholder dairy farms in Kikuyu Division of Kiambu District, 
Kenya was high. The incidence of retained placenta (26.6 \%) in this study was considered high compared to other studies in the same region (Odima, 1994; Eiler, 1997; Kanuya et al, 2000). Factors that could have led to this include mineral and vitamin deficiencies due to the low level of supplementation observed in this study.

The findings of this study revealed that animals with milk fever were more likely to develop retained placenta relative to those without milk fever. It has been suggested that this is due to

uterine atony in cows with milk fever and failure of expulsion of the placenta after parturition (Curtis et al, 1983). Cows that had retained placenta in the previous parturitions were more likely to develop retained placenta relative to those that had never developed retained placenta in the previous parturitions; these were inagreement with the findings of previous studies (Arthur et al, 1996, Fleischer et al, 2001). This may be due to the increased risk of developing placentitis thus leading to a firm attachment between the foetal cotyledons and maternal caruncles. It is therefore possible that, by reducing mineral and vitamin deficiencies through increased supplementation, the incidence of retained placenta in smallholder dairy cattle farms and the associated losses such as infertility can be reduced (le Blanc et al, 2002).

The incidence of dystocia (13.6\%) in this study was considered high. This high incidence may have been partly explained by the increased use of artificial insemination as was evident in this study, which may have led to the birth of largerand heavier calves thus predisposing the cows to developing dystocia as has previously been reported (Meyer et al, 2001). In this study, animals that developed dystocia were 58 times more likely to develop injuries to the birth canal relative to those with no dystocia. Most of these injuries were iatrogenic occurring during obstetrical manipulations to relieve dystocia. Furthermore, the traction applied on the

foetus could have led to physical injuries to the birth canal. The incidence of dystocia was also higher in animals that were bred by artificial insemination than those that were bred by natural mating and those that gave birth to male calves relative to when female calves were born. This could have been due to the larger calf sizes in both instances which predisposed the dams to developing dystocia. Therefore, in order to reduce the incidence and losses associated with dystocia, such as loss of genetic material from the death of calves and dams and veterinary costs, smallholder dairy farmers should be 
advised to select semen for artificial insemination from bulls based on calving ease and the size of the dams.

The incidence of milk fever in this study was considered within the normal range as reported earlier (Kelton et al, 1998). Improved genetics from artificial insemination resulting in higher producing animals without adequate supplementation as was evident in this study could have led to the occurrence of milk fever in this study. The highest incidence of milk fever was found in cows in their fourth lactation which was in agreement with previous reports on this condition (Radostits et al, 2000). Most328 farmers in this study were advised to give their animals formulations with high phosphorus during the dry period as a means of preventing milk fever; however this has been reported to increase the risk of developing milk fever by up to 6-9 times (Lean et al, 2006). Thus to reduce the incidence and losses associated with milk fever, smallholder farmers should be advised on the proper formulations to give their animals based on their levels and stage of production. In addition, they should be advised on what group of animals are most at risk based on age and stage of lactation.

The incidence of downer cow syndrome was considered high. Animals with milk fever were more likely to develop downer cow syndrome relative to those that did not develop milk fever. This was in agreement with the findings of previous studies(Radostits et al, 2000; Fleischer et al, 2001; Houe et al, 2001). In addition, cows that were not given supplemental feed during the pre-parturient period were more likely to develop downer cow syndrome relative to those who were given supplemental feed. Thus the provision of supplements just as for milk fever would assist in reducing the incidence and losses associated with downer cow syndrome.

The incidence of clinical mastitis encountered during the study was considered within the normal range. The most common organisms isolated were Escherichia coli and Klebsiella spp accounting for $70.59 \%$ of the isolates. This could have been due to hyperketonaemia present during this phase of production as has been reported previously (Harmon, 1984; Janosi et al, 2003; Nikolic et. al., 2003; Huszenicza et al, 2004). The low level of hygiene in the cow sheds and practised by the workers as observed in this study could also have led to the high incidence of clinical coliform mastitis (Elbers et al, 1998). Therefore, to reduce the incidence and losses associated with periparturient mastitis, farmers should be advised to improve the hygiene of their cattle sheds and milking procedures. 
The incidence of metritis at $7.28 \%$ was similar to reports from other studies (Odima, 1994, Kelton et al, 1998; Shiferaw et al, 2005). Animals that developed retained placenta were 5 times more likely to develop metritis. This could have been due to the unsanitary practices in the relief of retained afterbirth as had been reported in previous studies (Peeler et al, 1994). In addition, animals with dystocia were more likely to develop metritis; this could have been due to the resultant uterine atony that delayed the expulsion of uterine contents post calving and also injury and contamination of the uterus when obstetrical hygienic practices were not observed during the relief of dystocia as has been reported previously (Peeler et al, 1994; Bruun et al., 2002).

The incidence of stillbirths in this study of $5.8 \%$ was similar to other studies that had reported an incidence of 7 percent in United States dairy herds (Meyer et.al, 2000). The birth of a male offspring was associated with this condition which was in agreement with the findings of previous studies (Meyer et al, 2000; Meyer et al, 2001; Hansen et al, 2004). This may have been as a result of their relatively larger body size (Meyer et al., 2001).

Incidence of uterine and vaginal prolapse of $4.94 \%$ was agreeable with the findings of other workers (Markusfeld, 1987; Gardner et al, 1990). In this study, the incidence of prolapse was positively associated with the dry season. This may have been due to the fact that the poor nutrition during the dry season would have led to loss of body condition and perivaginal fat that is important in supporting the uterus and vagina within the pelvic cavity. To reduce the incidence and losses associated with uterine prolapse such as mortality, smallholder farmers should be advised and encouraged to employ ways of storing feed during the wet season when forage is abundant such as by making hay or silage, so that it can be used during the dry season. In addition they should be educated on the need for prompt treatment of cases of uterine prolapse in order to reduce mortality as was observed in this study.

The incidence of periparturient haemorrhage in the study was $3.4 \%$. Animals that developed dystocia were 10.5 times more likely to develop periparturient haemorrhage. This was in agreement with previously published reports (Njenga and Tsuma, 2004). Most of the cases were iatrogenic and occurred when injuries occurred on blood vessels in the reproductive tract during manipulation of the foetus in order torelieve the dystocia

The incidence of physiological oedema was $3.2 \%$ with only 5 out of the 8 cases being severe enough to warrant intervention.

Ethiop. Vet. J., 2012, 16 (2), 85-102 
The incidence of cystic ovarian disease of $0.9 \%$ was lower than reports in temperate countries where incidences of between 1 to $18.8 \%$ were reported (Garverick, 1997; Kelton et al, 1998). This may have been due to the low level of milk production of dairy cattle in the smallholder sector relative to dairy cattle in the temperate countries that leads to less stress post partum. In addition, as per the study design, animals in this study were examined up to 3 weeks post partum while indeed cystic ovarian disease has been reported to occur much later post partum (Hafez and Hafez, 2000); thus some of the animals may have developed the condition in the postpartum period beyond three weeks but was not diagnosed.

The incidence of uterine torsion at $0.9 \%$ was considered low. This may have been due to the fact that most farms had non slippery floors either made of stones or earthen floors. The chances of cows falling in such circumstances were therefore reduced. Frazer et al (1996) had reported that Friesians were at an increased risk of developing uterine torsion. Despite them being the predominant breed in this study, the incidence of uterine torsion was low. This implies the existence of other factors leading to the occurrence of uterine torsion.

In this study, the incidence of ketosis was very low. This low incidence may have been due to the relatively low milk production in smallholder dairy cattle relative to intensively reared dairy cattle; this would have led to reduced chances of the cows having a negative energy balance and developing ketosis (Hafez and Hafez, 2000). Furthermore, the relatively low average body condition score of cows in this study could also have contributed to the low incidence. Ketosis has also been associated with high level concentrate feeding (Arthur et al, 1996; Hafez and Hafez, 2000; Seifi et. al., 2007; Guo et al., 2008; Ospina et. al., 2010; Rollin et. al., 2010;), since this was low in the smallholder dairy cattle farms it could have contributed to the low incidence.

No case of abomasal displacement was encountered in this study. This could be attributed to the low level feeding of grain concentrate and the predominantly high roughage diets fed to the animals in the smallholder dairy production system relative to intensively reared dairy cattle. In addition, the feeding of grain concentrate was erratic in the farms where this was done.

In conclusion, there was a high incidence of periparturient conditions among smallholder dairy cattle herds in Kikuyu division of Kiambu district with downer cow syndrome, dystocia, mastitis, metritis, milk fever and retained 
placenta being the most common conditions encountered. The agro ecological zone, stall-feeding, the birth of male calves and lack of supplementation had an effect on the occurrence of periparturient conditions. In addition, conditions such as milk fever and dystocia did predispose to the occurrence of other periparturient conditions. Further research needs to be carried out so as to determine the impact of these diseases on the productivity and performance of cattle in the smallholder dairy production system and the dairy sector as a whole in Kenya.

\section{Acknowledgements}

Our appreciation goes to all the smallholder dairy farmers in Kikuyu Division, Kiambu District who participated in the study. We thank the staff of Kikuyu Dairy Society who provided the link with the farmers. This study was supported by the University of Nairobi.

\section{References}

Arthur, G.H., Noakes D.E. and Pearson H., 1996. Dystocia and other disorders associated with parturition. In: Veterinary Reproduction and Obstetrics.(Therigenology) 6th edition. W.B. Saunders, London.

Bruun J., Ersbøll A.K., Alban L., 2002. Risk factors for metritis in Danish dairy cows. Prev. Vet. Med. 54, 179-190.

Curtis, C.R., Erb H.N., Sniffen C.J., Smith R.D., Powers P.A., Smith M.E., Hillman R.B., and Pearson E.J, 1983. Association of periparturient hypocalcaemia with eight periparturient disorders in Holstein cows. J. Am. Vet. Med. Assoc. 183, 559561.

Dohoo I.R.,. Ducrot C., Fourichon C., Donald A. and Humik D. 1996. An overview of techniques for dealing with large numbers of independent variables in epidemiologic studies. Prev. Vet. Med. 29, 221-239

Eastern Africa agricultural productivity project (EAAPP) 2010. Research grant manual. iii

Eiler, H. 1997. Retained placenta. in Current Therapy in Large Animal Theriogenology. Pages 340-348

Ethiop. Vet. J., 2012, 16 (2), 85-102 
Elbers A.R., Miltenburg J.D., De Lange D., Crauwels A..P, Barkema H.W. and Schukken Y.H., 1998. Risk Factors for Clinical Mastitis in a Random Sample of Dairy Herds from the Southern Part of the Netherlands. J. Dairy Sci. 81, 420-426.

Erb, H.N., Smith R.D., Oltenacu P.A., Guard C.L., Hillman R.B., Powers P.A., Smith M.C. and White M.E., 1985. Path model of reproductive disorders and performance, milk fever, mastitis, milk yield, and culling in Holstein cows. J. Dairy Sci. 68, 3337-3349.

Fleischer, P., Metzner M., Beyerbach M., Hoedenmaker M. and Klee W., 2001. The relationship between milk yield and the incidence of some diseases in dairy cows. J. Dairy Sci. 84, 2025-2035.

Frazer G.S., Perkins N.R., Constable P.D., 1996. Bovine uterine torsion: 164 hospital refferal cases. Theriogenology. 46, 739-758.

Gardner, I.A., Reynolds J.P., Risco C.A. and Hird D.W., 1990. Patterns of uterine prolapse in dairy cows and prognosis after treatment. J. Am. Vet. Med. Assoc. 197,1021-1024.

Garverick H.A. 1997. Ovarian Follicular Cysts in Dairy Cows. J. Dairy Sci. 80, 9951004.

Goff, J.P. and Horst RL., 1997. Physiological changes at parturition and their relationship to metabolic disorders. J. Dairy Sci. 80, 1260-1268.

Guo J., Peters R.R. and Kohn R.A., 2008. Modeling nutrient fluxes and plasma ketone bodies in periparturient cows. J. Dairy Sci. 91, 4282-4292.

Hafez B. and Hafez E.S.E., 2000. Reproduction failure in females. In: Reproduction in farm animals. 7th edition. Lippincott Williams and Wilkins, Baltimore. Pp 263264.

Hansen, M., Lund M.S., Pedersen J. and Christensen L.G., 2004. Genetic parameters for stillbirth in Danish Holstein cows using a Bayesian Threshold model. J. Dairy Sci. 489 87, 706-716.

Harmon, R.J., 1984. Coliform mastitis-A challenge for dairymen and researchers. Dairy Food and Sanit. 4, 4-6.

Houe, H., Ostegaard S., Thilsing-Hansen T., Jorgensen R.J., Larsen T., Sorensen J.T., Agger J.F. and Blim J.Y., 2001. Milk fever and subclinical hypocalcaemia - an evaluation of parameters on incidence risk, diagnosis, risk factors and biological 
effects as inputs for a decision support system for disease control. Acta Vet. Scan. 42, 1- 29.

Huszenicza, G., Janosi S, Gaspardy A. and Kulscar M., 2004. Endocrine aspects inpathogenesis of mastitis in postpartum dairy cows. Anim. Rep. Sci. 82-83, 389400

Janosi, S., Kulcsar M., Korodi P., Katai L., Reiczigel J., Dieleman S.J., Nikolic J.A., Salyi G., Ribiczey-Szabo P. and Huszenicza G., 2003. Energy imbalance related predisposition to mastitis in group-fed high-producing postpartum dairy cows. Acta Vet. Hung. 51, 409-424.

Kanuya, N.L., Kessy B.M., Hegeko S.B.P., Mdoe N.S.Y. and Aboud A.A.O., 2000. Suboptimal performance of dairy cattle kept in smallholder herds in a rural highland area of northern Tanzania. Prev. Vet. Med. 45, 183-192.

Kimura K., Reinhardt T.A. and Goff J.P., 2006. Parturition and hypocalcaemia blunt calcium signals in immune cells of dairy cattle. J. Dairy Sci. 89: 2588-2595.

Kelton D.F., Lissemore K.D. and Martin E.R., 1998. Recommendations for recording and calculating the incidence of selected clinical diseases of dairy cattle. J. Dairy Sci. 81, 2502-2509.

LeBlanc S. J., Duffield T.F., Leslie K.E., Bateman K.G., TenHag J., Walton J.S., and Johnson W. H., 2002. The Effect of Prepartum Injection of Vitamin E on health in transition dairy cows. J. Dairy Sci. 85: 1416-1426.

Lean I. J., DeGaris1 P. J., McNeil D. M. and Block E., 2006. Hypocalcemia in dairy cows: Meta-analysis and dietary cation anion difference theory revisited. J. Dairy Sci. 89, 669-684.

Markusfeld O., 1987. Periparturient traits in seven high yielding dairy herds. Incidence rates, association with parity and inter-relationships among traits. J. Dairy Sci. 70, 158-166.

Mars Group Kenya. 2012. Livestock population by type and group. Marsgroupkenya. org

Meyer, C.L., Berger P.J. and Koehler K.J., 2000. Interactions among factors affecting stillbirths in Holstein cattle in the United States. J. Dairy Sci. 83, 2657-2663.

Meyer, C.L., Berger P.J., Koehler K.J., Thompson J.R. and Sattler C.G., 2001. Phenotypic trends of stillbirths for Holsteins in the United States. J. Dairy Sci. 84,512-523.

Ethiop. Vet. J., 2012, 16 (2), 85-102 
Nikolic, J.A., Kulscar M., Nedic O., Janosi S. and Huszenica G., 2003. Periparturient endocrine and metabolic changes in healthy cows affected by mastitis. J. Vet. Med. Phys. Path. Clin. Med. 50, 22-29.

Njenga, J.M. and Tsuma V.T., 2004. Sudden death following rupture of mid uterine artery, in a bovine dystocia. Kenya Vet. 26, 27-28.

Odima, P.A., 1994. Reproductive performance of dairy cows and heifers in Kiambu district, Kenya. M.Sc. Thesis. University of Nairobi.

Ospina P.A., Nydam D.V., Stokol T., Overton T.R. 2010. Evaluation of non-esterified fatty acids and B-hydroxybutyrate in transition dairy cattle in the northeastern United States: Critical thresholds for prediction of clinical diseases. J. Dairy Sci. $93,546-554$

Peeler, E.J., Otte M.J. and Esslemont R.J., 1994. Inter-relationships of periparturient diseases in dairy cows. Vet. Rec.134, 129-132.

Radostits, O.M., Leslie K.E. and Fetrow J., 1994. Textbook of Herd health; Food animal production medicine. 2nd edition. W.B. Saunders, Philadelphia, PA,

Radostits, O.M., Gay C.C., Blood D.C. and Hinchcliff K.W., 2000. Veterinary Medicine. In: Textbook of the Diseases of Cattle, Sheep, Pigs and Horses. 9th edition. W.B. Saunders, London.

Rollin E., Berghaus R.D., Rapnicki P., Godden S.M., Overton M.W., 2010. The effect of injectable butaphosphan and cyanocobalamin on postpartum serum B-hydroxybutyrate, calcium, and phosphorus concentrations in dairy cattle. $J$. Dairy Sci. 93, 978-987.

Seifi H.A., LeBlanc S.J., Vernooy E., Leslie K.E., Duffield T.F., 2007. Effect of isoflupredone acetate with or without insulin on energy metabolism, reproduction, milk production, and health in dairy cows in early lactation. J. Dairy Sci. 90, 41814191

Shiferaw, Y., Tenhagen B.A., Bekana M. and Kassa T., 2005. Reproductive disorders of crossbred dairy cows in the central highlands of Ethiopia and their effect on reproductive performance. Trop. Anim. Hlth Prod. 37, 427-441.

Sisson S. and Grossman D., 1969. The anatomy of the domestic animals. 4th edition. W.B. Saunders Co. Pg 453 